\title{
Acute exacerbation of idiopathic pulmonary fibrosis associated with air pollution exposure
}

\author{
Kerri A. Johannson ${ }^{1,2,3}$, Eric Vittinghoff ${ }^{4}$, Kiyoung Lee ${ }^{5}$, John R. Balmes ${ }^{1,2}$, \\ Wonjun $\mathrm{Ji}^{6}$, Gilaad G. Kaplan ${ }^{3}$, Dong Soon Kim ${ }^{6}$ and Harold R. Collard ${ }^{1}$
}

Affiliations: ${ }^{1}$ Dept of Medicine, University of California San Francisco, San Francisco, CA, ${ }^{2}$ School of Public Health, University of California Berkeley, Berkeley, CA, and ${ }^{4}$ Dept of Biostatistics and Epidemiology, University of California San Francisco, San Francisco, CA, USA. ${ }^{3}$ Dept of Medicine, University of Calgary, Calgary, AB, Canada. ${ }^{5}$ Dept of Environmental Health, Seoul National University, Seoul, and ${ }^{6}$ Dept of Pulmonary and Critical Care Medicine, Asan Medical Center, University of Ulsan, Seoul, South Korea.

Correspondence: D.S. Kim, Dept of Pulmonary and Critical Care Medicine, Asan Medical Center, University of Ulsan, 388-1, Pungnap-2dong, Songpa-gu, Seoul, South Korea. E-mail: dskim615dagmail.com

ABSTRACT Acute exacerbations of idiopathic pulmonary fibrosis are associated with high mortality and are of unknown cause. The effect of air pollution on exacerbations of interstitial lung disease is unknown. This study aims to define the association of air pollution exposure with acute exacerbation of idiopathic pulmonary fibrosis.

Patients with idiopathic pulmonary fibrosis and corresponding air pollution data were identified from a longitudinal cohort. Air pollution exposures were assigned to each patient for ozone, nitrogen dioxide, particulate matter, sulfur dioxide and carbon monoxide based on geo-coded residential addresses. Cox proportional hazards models were used to estimate the association of air pollution exposures and acute exacerbations.

Acute exacerbation was significantly associated with antecedent 6-week increases in mean level, maximum level and number of exceedances above accepted standards of ozone (hazard ratio (HR) 1.57, 95\% CI 1.09-2.24; HR 1.42, 95\% CI 1.11-1.82; and HR 1.51, 95\% CI 1.17-1.94, respectively) and nitrogen dioxide (HR 1.41, 95\% CI 1.04-1.91; HR 1.27, 95\% CI 1.01-1.59; and HR 1.20, 95\% CI 1.10-1.31, respectively).

Increased ozone and nitrogen dioxide exposure over the preceding 6 weeks was associated with an increased risk of acute exacerbation of idiopathic pulmonary fibrosis, suggesting that air pollution may contribute to the development of this clinically meaningful event.

@ERSpublications

Acute exacerbation of idiopathic pulmonary fibrosis is associated with increased ozone and nitrogen dioxide exposure http://ow.ly/t1vzw

For editorial comments see page 956.

This article has supplementary material available from www.erj.ersjournals.com

Received: July 172013 | Accepted after revision: Oct 202013 | First published online: Oct 312013

Conflict of interest: Disclosures can be found alongside the online version of this article at www.erj.ersjournals.com

Copyright @ERS 2014 


\section{Introduction}

Idiopathic pulmonary fibrosis (IPF) is a progressive parenchymal lung disease of unknown cause with an estimated median survival of 2-3 years from the time of diagnosis [1]. It is the most common of the idiopathic interstitial pneumonias and increases in prevalence substantially with age [2]. Many patients with IPF experience sudden stepwise acute respiratory worsenings, which are associated with high mortality [3]. In about half of cases, a cause for the acute worsening (e.g. infection, pulmonary embolism or congestive heart failure) cannot be diagnosed. These idiopathic acute respiratory worsenings are termed acute exacerbations of IPF [4].

Preliminary evidence suggests that some cases of acute exacerbation of IPF may be triggered by occult viral infection [5], microaspiration [6] and procedures such as surgical lung biopsy [7]. However, in the majority of cases a trigger cannot be found. Exposure to environmental triggers, such as ambient air pollution, could be responsible for some of these cases.

The relationship between ambient air pollution and exacerbation of respiratory diseases, such as asthma and chronic obstructive pulmonary disease (COPD), is well established [8-11]. Few studies have investigated the effects of ambient air pollution on interstitial lung diseases, despite epidemiological data linking exposure to inhaled agents, such as cigarette smoke, organic antigens and metal and wood dusts to these conditions. In addition, translational data support a mechanistic relationship between air pollution exposure and the development of pulmonary fibrosis [12-14]. We hypothesised that the risk of acute exacerbations in patients with IPF would be higher following periods of increased air pollution exposure.

This study investigates the relationship between ambient air pollution exposure (ozone $\left(\mathrm{O}_{3}\right)$, nitrogen dioxide $\left(\mathrm{NO}_{2}\right)$, particles with a 50\% cut-off aerodynamic diameter of $<10 \mu \mathrm{m}$ (PM10), sulfur dioxide $\left(\mathrm{SO}_{2}\right)$ and carbon monoxide (CO)) and acute exacerbations of IPF in a large, well-characterised cohort with contemporaneous clinical and ambient air pollution data.

\section{Materials and methods \\ Study cohort}

Patients with IPF were identified from an ongoing institutional review board-approved longitudinal cohort developed at Asan Medical Center in Seoul, South Korea. Informed consent was waived as this was a retrospective observational study of existing data. The local institutional review board approved the study. The diagnosis of all enrolled patients was reconfirmed as IPF according to American Thoracic Society/ European Respiratory Society/Japanese Respiratory Society/Latin American Thoracic Association consensus criteria [1]. Patients were excluded if the baseline forced vital capacity (FVC), smoking status, residential home address or corresponding air pollution exposure data were unavailable. A subgroup of patients identified for this study has been previously reported [3].

\section{Case definition}

Patients experiencing acute exacerbation during the follow-up period from January 1, 2001 to December 31, 2010 were considered cases. Acute exacerbations were defined by convention as a worsening of dyspnoea within 30 days of presentation, the presence of new pulmonary opacities on high-resolution computed tomography of the lung, and the exclusion of known causes for respiratory worsening such as infection, pulmonary embolism or congestive heart failure [4]. All patients underwent evaluation for respiratory infection with $69 \%$ having invasive sampling procedures. Due to potential effect modification between past and future exacerbations, patients experiencing more than one exacerbation only had their first event included as a case in the primary analysis. For each case, a pooled control population was constructed using all remaining patients in the cohort at the date of the case event, provided they had not yet experienced an acute exacerbation and did not develop one within 6 weeks following the date of the case event.

\section{Measurements}

Baseline clinical parameters were collected prospectively as part of the parent cohort and included patient demographics, smoking status (never, former or current), FVC \% predicted and diffusing capacity of the lung for carbon monoxide \% predicted. A current smoker was defined as a patient who was actively smoking at the time of enrolment into the study cohort. The date and clinical features of all acute exacerbations were recorded. Air pollution data for each of the five pollutants $\left(\mathrm{O}_{3}, \mathrm{NO}_{2}, \mathrm{PM}_{10}, \mathrm{SO}_{2}\right.$ and CO) were measured prospectively at Tele-Monitoring-Systems (TMS) situated throughout Korea (data purchased from AirKorea, Incheon, Korea). Each TMS recorded hourly measurements of each pollutant during the study period. Ozone measurements were taken from the warmer months (April-September) and during an 8 -h period of daylight (10:00 h-18:00 h). Temperature and humidity values were obtained similarly at each TMS in a subgroup of patients where available. Hourly temperature and humidity 
measurements were averaged over the exposure period for each event. Each patient was geo-coded to the nearest available TMS using his/her residential address. Data from the nearest TMS provided each patient's exposure during the study period.

\section{Analysis}

Mean and maximum exposures were defined as the average or highest of all 1-h $\left(\mathrm{NO}_{2}\right.$ and $\left.\mathrm{SO}_{2}\right), 8-\mathrm{h}\left(\mathrm{O}_{3}\right)$ or 24-h (PM10 and CO) levels over the 42-day (6-week) period prior to acute exacerbation date (hereafter referred to as the "exposure period"), respectively. The number of exceedances above accepted standards was also determined for each pollutant over the exposure period according to published and welldocumented regulatory standards $[15,16]$. The 42-day exposure period was chosen a priori to account for a potential lag time between exposure and the development of symptoms, and to allow for symptom onset (and, therefore, probable exacerbation onset) dating to 30 days before presentation, as per the definition of acute exacerbation [4].

Cox proportional hazards models were used to estimate the effect of air pollution exposure on incidence of acute exacerbation. Follow-up for each patient began at the date of IPF diagnosis, and ended at lung transplantation, death or on December 31, 2010, whichever came first. Analyses were adjusted for smoking status and FVC, factors known a priori to be associated with risk of acute exacerbation in the parent cohort. As per the standard Cox model, controls for each event included all patients still at risk on the date of the event; thus, patients could serve as controls for exacerbations of other patients between the date of IPF diagnosis and 42 days before their own first event, or censoring. For example, if a patient was diagnosed with IPF on January 22, 2002 and experienced an acute exacerbation on August 6, 2008 they would serve as a control for any acute exacerbation occurring between their date of diagnosis and June 25, 2008. To ensure adequate exposure measurement, all cases and controls were required to have pollution data for at least 21 days of the 42-day exposure period before the event.

Pre-defined secondary analyses included using different inclusion criteria for cases (patients whose home address was within $15 \mathrm{~km}$ of the monitoring site; patients with exposure data that could be adjusted for average temperature and humidity), other cumulative exposure periods (1-8 weeks); different outcome definitions (all, i.e. first plus subsequent, acute exacerbations) and alternative published standards or guidelines for exceedance levels $[16,17]$. Two-pollutant models were run to assess the independent effects of exposure variables that were statistically significant in single-pollutant models. Secondary analyses used the same analytical approach as the primary analysis.

Identical methodology was used to assess the association of cumulative air pollution exposure with mortality, and to examine potential increases in acute exacerbation and mortality risk among patients with a history of earlier acute exacerbation, in all cases controlling for age, sex and FVC, which are known predictors of mortality. For these analyses, cumulative exposures were calculated over the entire period from IPF diagnosis to date of censoring. All data analysis was performed using STATA version 12.1 (StataCorp, College Station, TX, USA) and statistical significance was defined as a p-value $<0.05$.

\section{Results}

\section{Patient population}

505 patients with IPF were identified from the longitudinal cohort; 69 were excluded for missing baseline data $(n=22)$ or lack of air pollution exposure data $(n=47) .436$ patients were included in the final analysis, of which 75 experienced at least one acute exacerbation. A subset of patients $(n=13)$ experienced more than one exacerbation. Baseline clinical characteristics of patients who experienced acute exacerbation of IPF and those who did not are presented in table 1. Patients with acute exacerbation had lower baseline FVC and were more likely to have a history of prednisone use and/or been on therapy for gastro-oesophageal reflux disease (GORD) at baseline assessment. There was no difference in the proportion of current, ex- or neversmokers in the exacerbating versus nonexacerbating patients. Two patients without exacerbation underwent lung transplantation. The average distance from the patient's residence to the geo-code-assigned TMS was $7.2 \mathrm{~km}$ (see online supplementary fig. S1).

\section{Acute exacerbation incidence and outcomes}

There were 89 acute exacerbation events occurring over 1699 patient-years, for an incidence rate of 5.2 exacerbations per 100 patient-years. Acute exacerbation events were characterised by fever (53\%) and cough (37\%), and had an average duration of symptoms prior to diagnosis of 10.7 days. $49 \%$ of patients were admitted to the intensive care unit, $8 \%$ required noninvasive positive pressure ventilation and $45 \%$ required mechanical ventilation. Acute exacerbation was associated with high risk of subsequent acute exacerbation (hazard ratio (HR) 4.32, 95\% CI 2.33-7.98) and substantially decreased survival time (HR 6.14, 95\% CI 4.03-9.34). Short-term mortality was $37 \%$ at 1 month and $67 \%$ at 6 months. 
TABLE 1 Baseline patient characteristics

\begin{tabular}{lccc} 
Characteristic & Acute exacerbation & No acute exacerbation & p-value $^{\#}$ \\
\hline Subjects n & 75 & 361 & \\
Age years & $63.7 \pm 8.4$ & $62.8 \pm 7.9$ & 0.29 \\
Females & $17(23)$ & $74(20)$ & 0.67 \\
Smoking status & & & \\
$\quad$ Never & $26(35)$ & $89(25)$ & 0.20 \\
$\quad$ Former & $32(43)$ & $177(49)$ & \\
$\quad$ Current & $17(22)$ & $78(26)$ & $<0.001$ \\
FVC \% predicted & $69.3 \pm 17.7$ & $67.1 \pm 17.6$ & 0.11 \\
DLco \% predicted & $62.5 \pm 19.3^{+}$ & $202(56.0)$ & 0.003 \\
Prednisone & $56(74.7)$ & $192(53.2)$ & $<0.001$ \\
GORD treatment & $57(76.0)^{f}$ & & \\
\hline
\end{tabular}

Data are presented as mean \pm SD or $n(\%)$, unless otherwise stated. FVC: forced vital capacity; DLCo: diffusing capacity of the lung for carbon monoxide; GORD: gastro-oesophageal reflux disease. \#: overall tests of heterogeneity; ${ }^{\circledR}: \mathrm{n}=58 ;{ }^{+}: \mathrm{n}=338 ;{ }^{\S}$ : proton pump inhibitor or histamine 2 receptor $\left(\mathrm{H}_{2}\right)$-antagonist; ${ }^{f}: 11$ out of 57 on proton pump inhibitor, 46 out of 57 on $\mathrm{H}_{2}$-antagonist.

\section{Association of air pollution exposure with acute exacerbation risk}

Acute exacerbation of IPF was significantly associated with increased mean levels, maximum levels, and number of exceedances of $\mathrm{O}_{3}$ and $\mathrm{NO}_{2}$ during the exposure period (fig. 1). There were no consistent relationships between $\mathrm{PM} 10, \mathrm{SO}_{2}$ or $\mathrm{CO}$ and acute exacerbation of IPF. Mean $\mathrm{O}_{3}$ and $\mathrm{NO}_{2}$ were weakly correlated and both were statistically significant independent predictors of acute exacerbation in a twopollutant model. Hazard ratios for all five exposures remained consistent when cases were limited to only

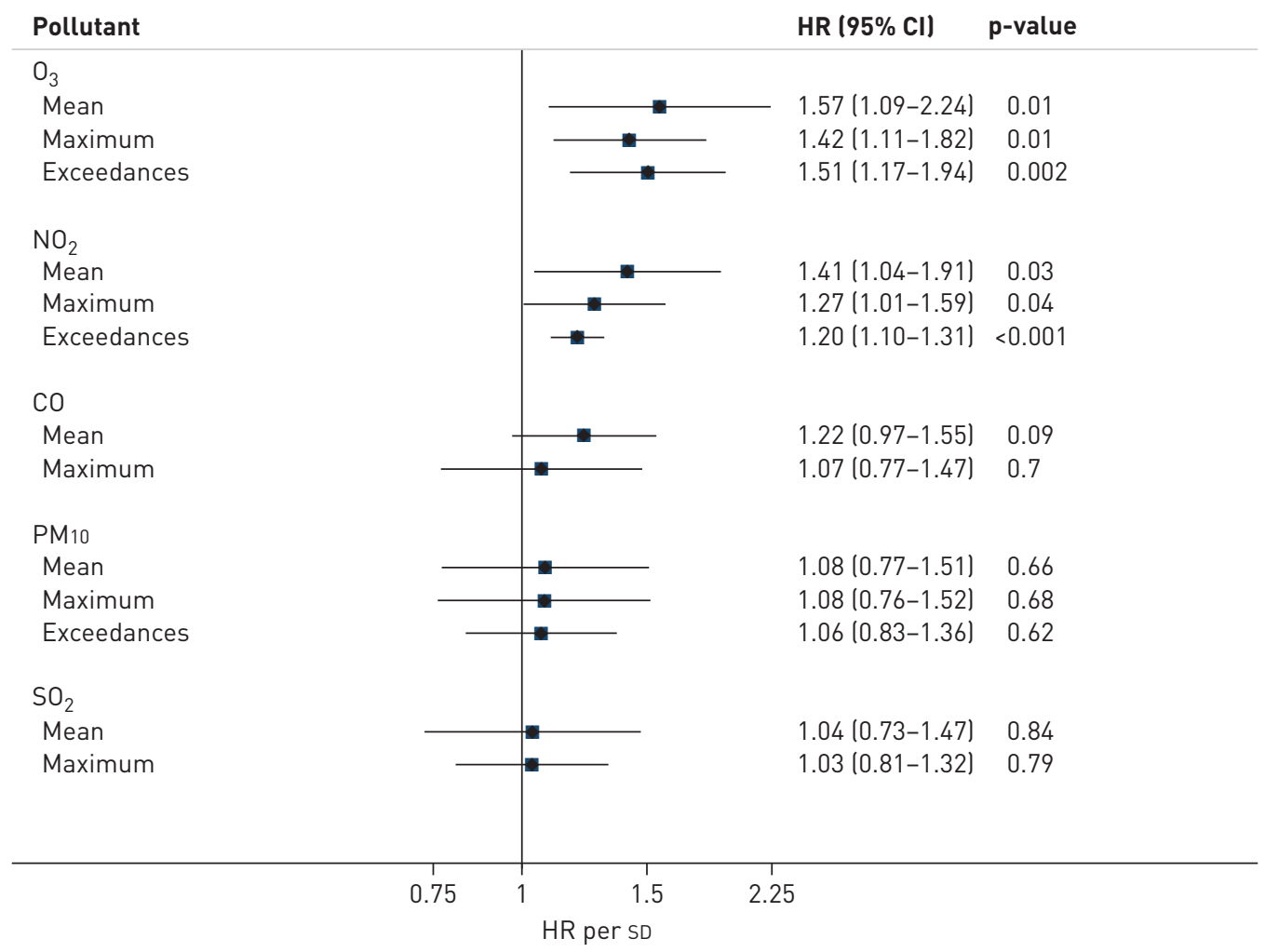

FIGURE 1 Ozone $\left(\mathrm{O}_{3}\right)$ and nitrogen dioxide $\left(\mathrm{NO}_{2}\right)$ exposure and risk of acute exacerbation. Mean levels, maximum levels and number of exceedances above standards for $\mathrm{O}_{3}$ and $\mathrm{NO}_{2}$ exposure over a 6-week period were associated with significantly increased risk for acute exacerbation of idiopathic pulmonary fibrosis. There was no association of particulate matter $<10 \mu \mathrm{m}$ in aerodynamic diameter (PM10), carbon monoxide (CO) or sulfur dioxide $\left(\mathrm{SO}_{2}\right)$ exposure with acute exacerbation risk. There were no exceedances above $\mathrm{CO}$ or $\mathrm{SO}_{2}$ standards. HR: hazard ratio. 
TABLE 2 Secondary analyses for air pollution exposure and risk of acute exacerbation

\begin{tabular}{|c|c|c|c|c|c|}
\hline Secondary analysis & $\mathrm{O}_{3}$ & $\mathrm{NO}_{2}$ & PM10 & CO & $\mathrm{SO}_{2}$ \\
\hline \multicolumn{6}{|c|}{ Within $15 \mathrm{~km}$ of $\mathrm{TMS}^{\#}$} \\
\hline Mean & $1.67(1.08-2.57)^{\S}$ & $1.47(1.06-2.05)$ & $0.97(0.67-1.40)$ & $1.29(1.00-1.67)$ & $0.97(0.65-1.45)$ \\
\hline Maximum & $1.57(1.14-2.16)^{\S}$ & $1.24(0.96-1.59)$ & $1.03(0.67-1.57)$ & $1.09(0.76-1.56)$ & $0.97(0.72-1.31)$ \\
\hline \multicolumn{6}{|c|}{$\begin{array}{l}\text { Adjusted for temperature and } \\
\text { relative humidity } \pi\end{array}$} \\
\hline Mean & $1.43(0.93-2.21)^{f}$ & $1.43(1.00-2.06)$ & $0.91(0.60-1.37)$ & $1.24(0.83-1.83)$ & $0.96(0.65-1.41)$ \\
\hline Maximum & $1.60(1.21-2.12)^{f}$ & $1.22(0.91-1.63)$ & $0.70(0.36-1.35)$ & $1.03(0.65-1.65)$ & $1.01(0.73-1.39)$ \\
\hline \multicolumn{6}{|c|}{ All acute exacerbations $^{+}$} \\
\hline Mean & $1.51(1.06-2.15)^{\# \#}$ & $1.40(1.06-1.86)$ & $1.17(0.84-1.63)$ & $1.29(1.03-1.60)$ & $1.09(0.80-1.49)$ \\
\hline Maximum & $1.43(1.15-1.78)^{\# \#}$ & $1.27(1.01-1.60)$ & $1.22(0.87-1.70)$ & $1.18(0.93-1.51)$ & $1.08(0.85-1.37)$ \\
\hline
\end{tabular}

Data are presented as hazard ratio $(95 \% \mathrm{Cl})$, where the hazard ratio is expressed per $\mathrm{SD}$ increase in measured exposure. $\mathrm{O}_{3}:$ ozone; $\mathrm{NO}_{2}:$ nitrogen dioxide; PM10: particles with a 50\% cut-off aerodynamic diameter of $10 \mu \mathrm{m}$; CO: carbon monoxide; $\mathrm{SO}_{2}$ : sulfur dioxide; TMS: Tele-Monitoring System. ${ }^{\#}: n=66 ;{ }^{\top}: n=51 ;{ }^{+}: n=89 ;{ }^{\S}: n=42 ;{ }^{f}: n=33 ;{ }^{\# \#}: n=55$.

those occurring within $15 \mathrm{~km}$ of a monitoring station, those able to be corrected for temperature and humidity, or when all acute exacerbations (including those occurring in patients who had previously experienced an acute exacerbation) were included (table 2). $\mathrm{O}_{3}$ and $\mathrm{NO}_{2}$ exposures remained generally associated with acute exacerbation when varying the exposure period from 1 to 8 weeks prior to acute exacerbation diagnosis (fig. 2 and online supplementary table S1). The associations with $\mathrm{O}_{3}$ and $\mathrm{NO}_{2}$ were also consistent when exceedance analyses were performed according to alternative published reference standards or guidelines (online supplementary table S2). Finally, these associations remained consistent when adjusted for history of prednisone and/or GORD therapy use (data not shown).

\section{Association of cumulative air pollution exposure and mortality}

There were no statistically significant relationships between air pollution exposure and mortality. Hazard ratios for mean $\mathrm{O}_{3}$ and $\mathrm{NO}_{2}$ exposure were 1.03 (95\% CI $0.90-1.17$ ) and 0.97 (95\% CI $0.86-1.10$ ), respectively, while those for maximum $\mathrm{O}_{3}$ and $\mathrm{NO}_{2}$ exposures were 1.02 (95\% CI 0.90-1.16) and $1.06(95 \%$ CI $0.93-1.20$ ), respectively.

\section{Discussion}

Our study demonstrates a significant relationship between ambient $\mathrm{O}_{3}$ and $\mathrm{NO}_{2}$ levels and acute exacerbation of IPF, suggesting that increased exposure to these pollutants contributes to the development of acute exacerbation in some patients. The magnitude of the associated risk is comparable to what has been reported for exacerbation of other chronic lung diseases $[10,18,19]$. To our knowledge this is the first report describing this association in IPF. Air pollution is a potentially modifiable risk factor either via behavioural adaptation of the patient (i.e. exposure avoidance) or community-level reductions in exposure through environmental policy. Our findings suggest that reductions in ambient air pollution exposure may decrease the risk of acute exacerbation and improve the morbidity associated with IPF.

Based on the clinical presentations of patients with acute exacerbations of IPF, we hypothesised that ambient air pollution-associated events, unlike acute exacerbation of asthma or acute myocardial infarction, would have a delayed clinical presentation. The 6-week exposure period was defined a priori based on the assumption that an interval of up to 30 days might occur between symptom onset (and therefore likely exposure risk) and time of diagnosis, and to allow for a potential lag-time from pollutant exposure to symptom development. Sensitivity analyses varying the exposure period from 1 to 8 weeks prior to acute exacerbation demonstrated a consistent association, strengthening the results, and suggesting that the exposure period of highest risk lies between 2 and 8 weeks before diagnosis. Because $\mathrm{O}_{3}$ levels are known to be lower during the winter and at night, outcomes were analysed in relation to peak $\mathrm{O}_{3}$ concentration using 8-h midday levels during the warmer months only, an approach commonly used in epidemiological studies of $\mathrm{O}_{3}$ $[20,21]$. For the exceedance analyses, the United States Environmental Protection Agency National Ambient Air Quality Standards were chosen a priori because they are regulatory standards and not merely guidelines.

$\mathrm{O}_{3}$ and $\mathrm{NO}_{2}$ are known risk factors for poor outcomes and exacerbations in chronic lung diseases [22-25]. A long-term population analysis found a relative risk of respiratory-related death of 1.04 for every $10 \mathrm{ppb}$ increase in $\mathrm{O}_{3}$ [20]. $\mathrm{O}_{3}$ has been associated with increasing risk for the development of airways diseases like 
a)

Exposure

$\operatorname{HR}(95 \% \mathrm{CI})$

p-value

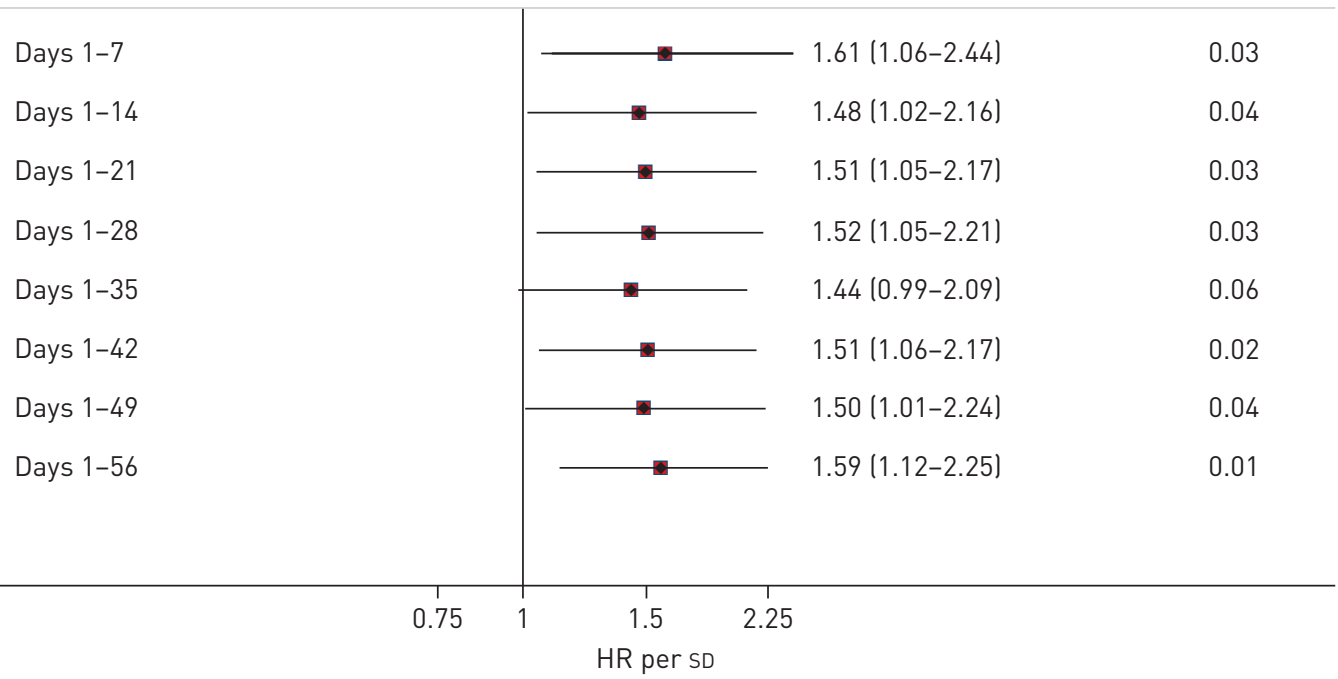

b)

Exposure

$\operatorname{HR}(95 \% \mathrm{CI})$

p-value

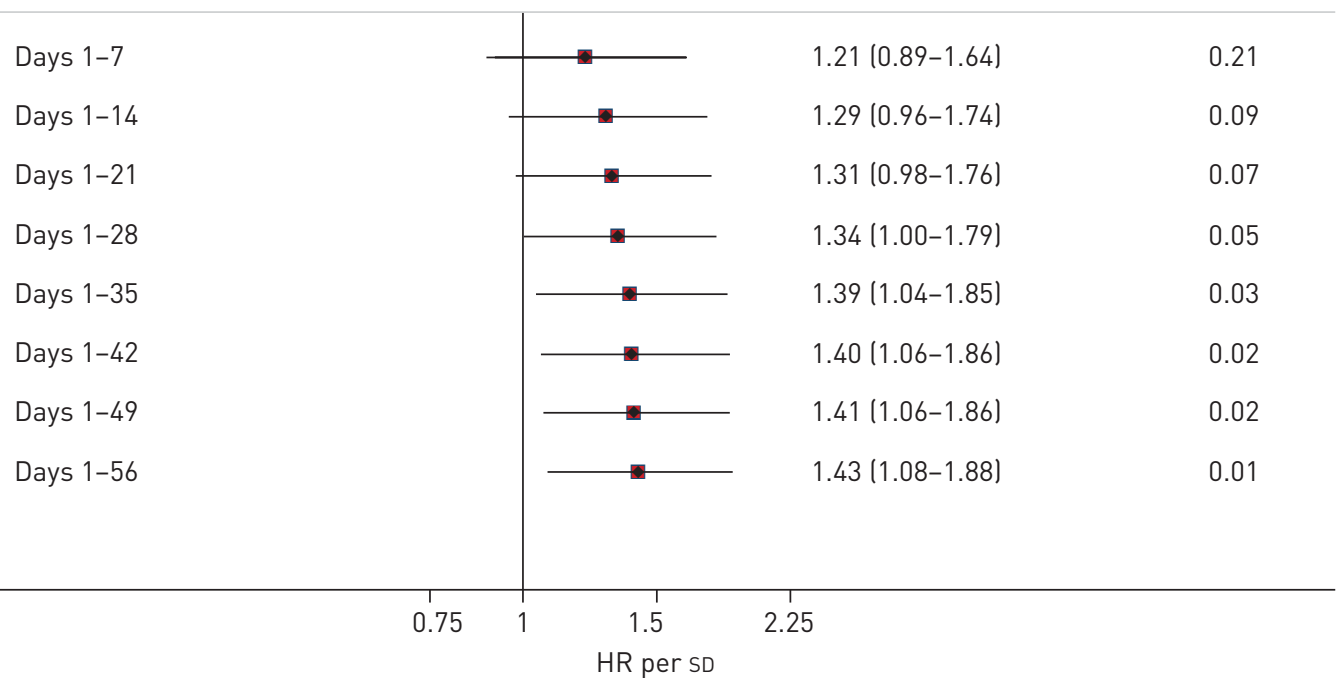

FIGURE 2 Secondary sensitivity analyses for a) ozone and b) nitrogen dioxide exposures and risk of acute exacerbation, which show a consistent relationship with acute exacerbation across multiple cumulative exposure periods. HR: hazard ratio.

asthma and with increased exacerbation risk in asthma and cystic fibrosis $[18,23,26]$. $\mathrm{NO}_{2}$ exposure has been associated with increased risk of respiratory hospitalisation in COPD and asthma, and traffic-related air pollution exposure increases the risk of post lung transplant bronchiolitis obliterans syndrome [8-10, 19]. It is not entirely surprising, therefore, that exposure to $\mathrm{O}_{3}$ and $\mathrm{NO}_{2}$ appear to contribute to worsening of IPF.

Air pollution exposure may trigger acute exacerbation of IPF via the production of excess reactive oxygen species (ROS), such as hydroxide radical and superoxide anion [27]. Intrinsic antioxidants, such as glutathione, are generally capable of counterbalancing the effects of ROS, but when the production of ROS exceeds the lung's ability to remove them, cellular damage ensues. Patients with IPF have evidence of reduced antioxidant capacity, suggesting they may have increased vulnerability to excess ROS caused by exposure to air pollution [28].

The greatest modifiable source of $\mathrm{O}_{3}$ and $\mathrm{NO}_{2}$ in the industrialised world is from motor vehicle emissions. While our results do not inform strategies for exposure reduction, they do suggest that patients with IPF might benefit from avoiding excess pollutant exposure perhaps through reduced physical exertion or staying 
indoors on days with high air pollution levels. In addition, IPF patients might benefit from relocating to environments with lower emissions and better air quality. At a policy level, adherence to and enforcement of air quality standards may reduce the incidence of acute exacerbation of IPF. Understanding more fully the implications of these findings will require the continued integration of the fields of clinical research, environmental health and public policy.

The IPF cohort used for this study is well-characterised and probably represents the largest such cohort available for this type of analysis, but the sample size is still relatively small for air pollution studies. This makes the consistent relationship between $\mathrm{O}_{3}$ and $\mathrm{NO}_{2}$ exposure and acute exacerbation all the more striking. The consistency of hazard ratios across sensitivity analyses further strengthens the reliability of the results. It is possible that significant associations with fine or ultrafine particulate matter were missed, as the only particulate matter metric available for this analysis was PM10. There is the potential for exposure misclassification given that exposure estimates were based on regional air quality monitoring data and, therefore, could not account adequately for individual-level exposure differences such as time spent indoors and in traffic or subregional geographical variation. Reported residential addresses were confirmed before geo-coding, but some patients may have moved or spent significant amounts of time in other locations. Due to the retrospective nature of this study, other potential sources of pollutant exposures (e.g. cooking stoves and biofuels) could not be assessed. Also, it was not possible to adjust for temperature and relative humidity for the whole cohort, but a sensitivity analysis in the subgroup with available temperature and humidity data showed a consistent relationship between air pollution and acute exacerbation.

We did not find any relationship between cigarette smoking, the use of immunosuppressive medications or the use of anti-acid therapies and the risk of acute exacerbation. However, our study's small numbers and lack of detailed data regarding cigarette smoking and immunosuppressive medication use at the time of exacerbation limit any conclusions regarding these relationships. These questions can best be addressed in large prospective trials.

In summary, these data suggest that exposure to $\mathrm{O}_{3}$ and $\mathrm{NO}_{2}$ contributes to the risk of acute exacerbation of IPF, and we speculate that air pollution represents one of a series of factors (e.g. viral infection and microaspiration) that serve as triggers for these clinically important events. It is possible that variations in ambient pollutant exposure contribute to differences in rates of acute exacerbation by geographical region, but further study is required to evaluate this relationship. $\mathrm{O}_{3}$ and $\mathrm{NO}_{2}$ have the potential for mitigation through behavioural and environmental policy changes, which could reduce the risk to these susceptible patients. Further research is needed to validate these findings and to better delineate the pathobiological role of air pollution in IPF.

\section{Acknowledgements}

The authors would like to thank Y. Hwang from the Graduate School of Public Health, Seoul, South Korea, for efforts in obtaining, translating and organising the air pollution data. The authors would also like to thank T.E. King Jr (University of California, San Francisco, CA, USA) and C. Carlsten (University of British Columbia, Vancouver, BC, Canada) for their thoughtful review of the manuscript.

\section{References}

Raghu G, Collard HR, Egan JJ, et al. An official ATS/ERS/JRS/ALAT statement: idiopathic pulmonary fibrosis: evidence-based guidelines for diagnosis and management. Am J Respir Crit Care Med 2011; 183: 788-824.

2 Raghu G, Weycker D, Edelsberg J, et al. Incidence and prevalence of idiopathic pulmonary fibrosis. Am J Respir Crit Care Med 2006; 174: 810-816.

3 Song JW, Hong SB, Lim CM, et al. Acute exacerbation of idiopathic pulmonary fibrosis: incidence, risk factors and outcome. Eur Respir J 2011; 37: 356-363.

4 Collard HR, Moore BB, Flaherty KR, et al. Acute exacerbations of idiopathic pulmonary fibrosis. Am J Respir Crit Care Med 2007; 176: 636-643.

5 Wootton SC, Kim DS, Kondoh Y, et al. Viral infection in acute exacerbation of idiopathic pulmonary fibrosis. Am J Respir Crit Care Med 2011; 183: 1698-1702.

6 Lee JS, Song JW, Wolters PJ, et al. Bronchoalveolar lavage pepsin in acute exacerbation of idiopathic pulmonary fibrosis. Eur Respir J 2012; 39: 352-358.

7 Kondoh Y, Taniguchi H, Kitaichi M, et al. Acute exacerbation of interstitial pneumonia following surgical lung biopsy. Respir Med 2006; 100: 1753-1759.

Brunekreef B, Holgate ST. Air pollution and health. Lancet 2002; 360: 1233-1242.

MacNee W, Donaldson K. Exacerbations of COPD: environmental mechanisms. Chest 2000; 117: Suppl. 2, 390S-397S.

10 Andersen ZJ, Bønnelykke K, Hvidberg M, et al. Long-term exposure to air pollution and asthma hospitalisations in older adults: a cohort study. Thorax 2012; 67: 6-11.

11 Schikowski T, Sugiri D, Ranft U, et al. Long-term air pollution exposure and living close to busy roads are associated with COPD in women. Respir Res 2005; 6: 152.

12 Diaz de Leon A, Cronkhite JT, Katzenstein AL, et al. Telomere lengths, pulmonary fibrosis and telomerase (TERT) mutations. PLoS One 2010; 5: e10680.

13 Garcia CK. Idiopathic pulmonary fibrosis: update on genetic discoveries. Proc Am Thorac Soc 2011; 8: 158-162. 
14 Ly H. Genetic and environmental factors influencing human diseases with telomere dysfunction. Int J Clin Exp Med 2009; 2: 114-130.

15 US Environmental Protection Agency. National Ambient Air Quality Standards. www.epa.gov/air/criteria.html Date last updated: December 14, 2012. Date last accessed: October 1, 2012.

16 Air Korea. Air Quality Standards. www.airkorea.or.kr/airkorea/eng/information/main.jsp?action=standard Date last accessed: October 1, 2012.

17 World Health Organization. Air Quality Guidelines - Global Update 2005. Copenhagen, WHO Regional Office for Europe, 2006. www.who.int/phe/health_topics/outdoorair/outdoorair_aqg/en/index.html Date last accessed: July $15,2013$.

18 Goss CH, Newsom SA, Schildcrout JS, et al. Effect of ambient air pollution on pulmonary exacerbations and lung function in cystic fibrosis. Am J Respir Crit Care Med 2004; 169: 816-821.

19 Nawrot TS, Vos R, Jacobs L, et al. The impact of traffic air pollution on bronchiolitis obliterans syndrome and mortality after lung transplantation. Thorax 2011; 66: 748-754.

20 Jerrett M, Burnett RT, Pope CA 3rd, et al. Long-term ozone exposure and mortality. N Engl J Med 2009; 360: $1085-1095$.

21 Berman JD, Fann N, Hollingsworth JW, et al. Health benefits from large-scale ozone reduction in the United States. Environ Health Perspect 2012; 120: 1404-1410.

22 Meng YY, Rull RP, Wilhelm M, et al. Outdoor air pollution and uncontrolled asthma in the San Joaquin Valley, California. J Epidemiol Community Health 2010; 64: 142-147.

23 Mann JK, Balmes JR, Bruckner TA, et al. Short-term effects of air pollution on wheeze in asthmatic children in Fresno, California. Environ Health Perspect 2010; 118: 1497-1502.

24 Gauderman WJ, Gilliland GF, Vora H, et al. Association between air pollution and lung function growth in southern California children: results from a second cohort. Am J Respir Crit Care Med 2002; 166: 76-84.

25 Pope CA 3rd, Ezzati M, Dockery DW. Fine-particulate air pollution and life expectancy in the United States. N Engl J Med 2009; 360: 376-386.

26 Tager IB, Balmes J, Lurmann F, et al. Chronic exposure to ambient ozone and lung function in young adults. Epidemiology 2005; 16: 751-759.

27 Grahame TJ, Schlesinger RB. Oxidative stress-induced telomeric erosion as a mechanism underlying airborne particulate matter-related cardiovascular disease. Part Fibre Toxicol 2012; 9: 21.

28 Beeh KM, Beier J, Haas IC, et al. Glutathione deficiency of the lower respiratory tract in patients with idiopathic pulmonary fibrosis. Eur Respir J 2002; 19: 1119-1123. 